\title{
Consumers’ Willingness to Pay for Renewable Energy: A Meta-Regression Analysis
}

Chunbo Ma ${ }^{* a}$, Abbie A. Rogers ${ }^{\mathrm{a}}$, Marit E. Kragt ${ }^{\mathrm{a}, \mathrm{c}}$, Fan Zhang ${ }^{\mathrm{a}}$, Maksym Polyakov ${ }^{\mathrm{a}}$, Fiona Gibson $^{\mathrm{a}}$, Morteza Chalak ${ }^{\mathrm{a}}$, Ram Pandit ${ }^{\mathrm{a}}$, Sorada Tapsuwan ${ }^{\mathrm{a}, \mathrm{b}}$

${ }^{a}$ Centre for Environmental Economics and Policy, School of Agricultural and Resource Economics, The University of Western Australia, Crawley WA 6009.

${ }^{\mathrm{b}}$ CSIRO Land and Water Flagship, Commonwealth Scientific and Industrial Research Organisation, Floreat WA 6014

${ }^{c}$ Agriculture Flagship, Commonwealth Scientific and Industrial Research Organisation, Floreat WA 6014

* Corresponding author:

chunbo.ma@uwa.edu.au

Phone: +61-8-6488-2534 


\title{
Consumers’ Willingness to Pay for Renewable Energy: A Meta-Regression Analysis
}

\begin{abstract}
Using renewable energy for domestic consumption has been identified as a key strategy by the Intergovernmental Panel on Climate Change to reduce greenhouse gas emissions. Critical to the success of this strategy is to know whether consumers are willing to pay to increase the proportion of electricity generated from renewable energy in their electricity portfolio. There are a number of studies in the literature that report a wide range of willingness to pay estimates. In this study, we used a meta-regression analysis to determine how much of the variation in willingness to pay reflects true differences across the population and how much is due to study design, such as survey design and administration, and model specification. The results showed that factors that influence willingness to pay, such as renewable energy type, consumers' socio-economic profile and consumers' energy consumption patterns, explain less variation in willingness to pay estimates than the characteristics of the study design itself. Because of this effect, we recommend that policy makers exercise caution when interpreting and using willingness to pay results from primary studies. Our meta-regression analysis further shows that consumers have significantly higher willingness to pay for electricity generated from solar, wind or generic renewable energy source (i.e. not a specific source) than hydro power or biomass.
\end{abstract}

Key Words: meta-regression, renewable energy, green electricity, valuation, willingness to pay

JEL Codes: C53, D62, Q40, Q48, Q51 


\section{Consumers’ Willingness to Pay for Renewable Energy: A Meta-Analysis}

\section{Introduction}

The Intergovernmental Panel on Climate Change (IPCC) has identified renewable energy (RE), such as wind farms and hydro power, as a key strategy to reduce greenhouse gas emissions (IPCC, 2014; Moomaw et al., 2011). Renewable energy sources can provide a number of intangible benefits, such as greater energy security, lower $\mathrm{CO}_{2}$ emissions (relative to fossil fuels) and continual innovation (IPPC, 2014; Wei et al., 2010). But, negative perceptions about the benefits of RE sources, higher prices and distrust in accreditation processes, for example, make traditional product marketing for RE more difficult (Bloom and Novelli, 1981; Rothschild, 1979; Wiener and Doescher, 1991).

Numerous studies have investigated people's stated intentions to purchase electricity from renewable sources (e.g. Aravena et al., 2012; MacMillan et al., 2006). These studies employed stated preference surveys to elicit respondents’ willingness to pay (WTP) for a future change in a non-market good or service. Stated preference techniques that are predominately applied to identify preferences for RE are: choice experiments - which elicits the value of the characteristics of a good - and contingent valuation - which values the good as a whole (Bateman et al. (2002). Estimates of WTP for RE vary widely between studies. For example: Batley et al. (2001) found that WTP varies with social status and income, while Ek (2005) found that age, income and environmental awareness are the main individual characteristics affecting WTP for RE. Borchers et al. (2007) showed that the type of RE significantly influences WTP and Roe et al., (2001) report that WTP for emissions reduction increases when those reductions are from increased reliance upon renewable fuels. However, these conclusions are based on results from individual studies, and may not be valid across studies. If WTP is a function of study design, errors will arise when transferring estimates from one site to another.

The variation in these empirical WTP estimates does not provide the policy maker with a constructive, general understanding of consumer behaviour towards RE. Before using WTP 
values for policy making or benefit transfer ${ }^{1}$, a number of questions need to be addressed: what is the likely range of individual values for a particular study site or energy source; which explanatory factors should be considered; are there gaps in the data that may skew the recommended values. A tool to address these questions that has gained considerable traction in the literature is meta-analysis. Meta-analysis is a method that systematically summarises, in a quantitative manner, evidence across empirical studies (Glass, 1976).

A quantitative type of meta-analysis, 'meta-regression analysis', has the intuitive appeal of combining, sometimes widely scattered, empirical evidence on a particular subject and in increasing the statistical power of hypothesis testing when a large number of independent studies that use different data sets and methods are combined. More importantly, by controlling for variations in characteristics across independent studies, meta-regression analysis can furnish more insight into what factors explain the variation of results from different studies. Ultimately, it can provide a more informed consensus about the actual size of the effect (or dependent variable) under study. As such, meta-regression analysis provides a greater explanatory power than listing individual results or a standard narrative literature review (Stanley, 2001).

Nelson and Kennedy’s (2009) meta-regression analysis of environmental economics did not include any studies of WTP for RE in their sample of 140 studies. A working paper by Sundt and Rehdanz (2014) reports on a meta-regression analysis conducted WTP for RE. This paper progresses previous literature by completing a more comprehensive meta-regression analysis based on a substantially larger sample. We include a richer set of controls for differences in survey design (e.g. pilot, opt-out), elicitation format, administration procedure (e.g. mail, face-to-face, phone) and modelling specifications of the primary studies. We show that these aspects explain a large proportion of the variation in WTP values across studies, which has significant policy implications. Furthermore, our study differentiates itself from others by including multiple types of RE sources (solar, wind, biomass and hydro power) in the meta-regression analysis.

We use meta-regression analysis to estimate an average WTP for RE sources and to determine what characteristics explain heterogeneity in WTP. We contribute to the literature by accounting for a variety of characteristics that may influence WTP, such as survey design

\footnotetext{
${ }^{1}$ The use of existing studies in project evaluation and policy analyses (Morrison et al. 2002). In benefit transfer, WTP estimates from one study site (the source of the data) are transferred to another site (the site of policy interest).
} 
characteristics, survey administration procedure, and stated preference elicitation format. We also include a range of RE sources, thus providing policy makers with a comprehensive picture of consumer preferences between sources. These WTP values of different sources of RE can be used by decision makers to bring prices of RE more in line with consumers' WTP. The structure of the paper is as follows: the methods are explained in the next section, followed by the econometric results in Section 3. The final two sections discuss the results and provide recommendations for policy.

\section{Methods}

This paper follows reporting protocols suggested by Nelson and Kennedy (2009) and Stanley et al. (2013). This first section outlines the search criteria for empirical studies and data. We then define the effect size and how it was calculated from each study. The selection of moderator variables and the appropriate model are then discussed, followed by the treatment of publication bias.

\section{Data collection and cleaning}

Primary studies were sought via a comprehensive search of the literature in the online databases Scopus, Web of Science and Google Scholar. Including Google Scholar allowed us to access the grey literature, including conference proceedings, working papers and research theses. In the search, key words reflecting the (stated-preference) valuation techniques included: willingness to pay, choice modelling, choice experiment, contingent valuation, preferences, non-market valuation and valuation. These were paired with search terms to reflect both specific and generic types of RE including: solar energy, solar panels, photovoltaic, solar; wind energy, wind power; geothermal energy, geo-thermal; biomass, bioenergy; wave energy, tidal energy; hydro power, hydro-electric, hydro; renewable energy, renewable and green power. The search terms were allocated between authors. The search was completed at 31 January 2014 and returned 149 primary studies to be considered for analysis.

The 149 primary studies were scrutinised on their study focus by two authors, independently. Only studies that estimated WTP for the supply of renewable energy (RE) were included in further analysis. Excluded were studies on non-renewable energy sources such as gas or nuclear power; and studies that did not estimate values for energy provision (e.g. studies that 
estimate WTP for RE projects without mentioning the amount of energy generated by such a project). We also excluded studies that estimated WTP specifically for positive or negative externalities associated with RE, or for characteristics of RE projects rather than the energy per se. For example, Susaeta et al. (2011) was not included in our final sample ${ }^{2}$ because their choice experiment looked at the impacts of $\mathrm{RE}$ on 'reduction of $\mathrm{CO}_{2}$ ' and 'improvement of forest habitat' instead of WTP for energy itself. Records that did not report the survey year, sample size, payment vehicle, or WTP estimates were also excluded from our analysis since these studies did not provide the information essential for our meta-regression analysis. This data cleaning process resulted in 29 primary studies and 142 WTP observations for further analysis (Table 1).

\footnotetext{
${ }^{2}$ Contrary to the analysis by Sundt and Rehdanz (2014).
} 
Table 1 - Primary studies included in the meta-regression analysis.

\begin{tabular}{|c|c|c|c|c|c|}
\hline & Author(s) & $\begin{array}{r}\text { Year } \\
\text { Published }\end{array}$ & $\begin{array}{l}\text { Country/ } \\
\text { Region }\end{array}$ & Source ${ }^{*}$ & $\begin{array}{c}\text { \# WTP } \\
\text { observations }^{\dagger}\end{array}$ \\
\hline 1 & Byrnes et al. & 1999 & USA & Journal of Environmental Planning and Management & 5 \\
\hline 2 & Hanley and Nevin & 1999 & Scotland & Energy Policy & 3 \\
\hline 3 & Zarnikau & 2003 & USA & Energy Policy & 4 \\
\hline 5 & Ivanova & 2005 & Australia & Proceedings of the ANSEE conference & 2 \\
\hline 6 & MacMilan et al. & 2006 & Scotland & Ecological Economics & 8 \\
\hline 7 & Borchers et al. & 2007 & USA & Energy Policy & 20 \\
\hline 8 & Navrud and Grønvik Bråten & 2007 & Norway & Revue d'économie politique & 6 \\
\hline 11 & Bollino & 2009 & Italy & The Energy Journal & 6 \\
\hline 12 & Soliño et al. & 2009a & Spain & Energy Policy & 4 \\
\hline 13 & Soliño et al. & $2009 b$ & Spain & Energy Policy & 1 \\
\hline 14 & Yoo and Kwak & 2009 & South Korea & Energy Policy & 2 \\
\hline 15 & Zografakis et al. & 2010 & Greece & Renewable and Sustainable Energy & 2 \\
\hline
\end{tabular}


Table 1 (cont.) - Primary studies included in the meta-regression analysis.

\begin{tabular}{|c|c|c|c|c|c|}
\hline & Author(s) & $\begin{array}{r}\text { Year } \\
\text { Published }\end{array}$ & $\begin{array}{l}\text { Country/ } \\
\text { Region }\end{array}$ & Source ${ }^{*}$ & $\begin{array}{c}\text { \# WTP } \\
\text { observations }^{\dagger}\end{array}$ \\
\hline 16 & Bigerna and Polinori & 2011 & Italy & USAEE Working Paper & 9 \\
\hline 17 & Hanemann et al. & 2011 & Spain & Climate Research & 1 \\
\hline 18 & Komarek et al. & 2011 & USA & Energy Policy & 9 \\
\hline 20 & Aldy et al. & 2012 & USA & Nature Climate Change & 1 \\
\hline 21 & Aravena et al. & 2012 & Chile & Energy Economics & 4 \\
\hline 22 & Cicia et al. & 2012 & Italy & Energy Policy & 9 \\
\hline 23 & Gracia et al. & 2012 & Spain & Energy Policy & 3 \\
\hline 26 & Zhang and Wu & 2012 & China & Energy Policy & 1 \\
\hline 27 & Kaenzig et al. & 2013 & Germany & Energy Policy & 2 \\
\hline 28 & Kontogianni et al. & 2013 & Greece & Energy Policy & 4 \\
\hline 29 & Kosenius and Ollikainen & 2013 & Finland & Energy Policy & 6 \\
\hline
\end{tabular}

${ }^{*}$ We included 25 studies that were published in peer-reviewed journals, $2 \mathrm{PhD}$ theses, 1 conference paper and 1 working paper; ${ }^{\dagger}$ This is the number of WTP estimates that each primary study provided for our final analysis (total 142). 


\section{Effect size definition and derivation}

In meta-analyses, the dependent variable is called 'effect size'. The effect size standardises findings across studies such that they can be directly compared. Any standardised index can be used as an effect size, such as: standardised mean difference, correlation coefficient, and odds-ratio (Field and Gillett, 2010; Rosenthal, 1991). In this study, the effect size is defined as “consumers' WTP to increase the proportion of electricity generated from RE in their electricity portfolio". The WTP values should be understood as a premium WTP rather than a gross WTP for the portfolio change; that is, how much more would consumers be willing to pay, on top of their current payment, per unit of electricity consumed. We calculated mean estimates of WTP for the proposed change in RE share. WTP values from contingent valuation studies are unambiguously mean estimates and could thus be used directly. However, choice experiments typically estimate marginal, rather than mean, values for the good under valuation. The choice experiment studies included in our analysis all estimated linear utility functions and included the proportion of RE in the portfolio as a continuous variable. We could therefore treat the estimated constant marginal WTP as a mean estimate for the considered range of RE share.

We used a systematic approach to convert the effect size for each observation, taking into account the differences in study year, study location, payment vehicle, payment frequency, payment duration, currency used (five types), and energy sources considered in the primary studies. The collected WTP values were converted to a consistent metric: US dollars per kWh in 2006 prices on a perpetual basis (i.e. ongoing payment) using the following steps:

1. Where provided in the primary studies, we collated annual household average electricity consumption data. For studies that did not provide this information, data on household average electricity consumption for each country/state/province in our sample was compiled from various other sources (EUROSTAT: Statistical Office of the European Union, US Energy Information Administration, Organisation for Economic Co-operation and Development, US Department of Energy and Census, UK Government, Australian Bureau of Resources and Energy Economics and Kenyan National Bureau of Statistics) for the same study year.

2. The Consumer Price Index for each country in our sample was obtained from various sources, including the sources used to compile average household electricity consumption. Reported WTP estimates were firstly converted to 2006 prices. The year 2006 was chosen 
as a baseline because the majority of surveys selected for the meta- analysis were conducted that year.

3. Assuming a 5 per cent annual discount rate, the perpetual payment for total annual consumption was calculated for each reported WTP estimate. This calculation was in the local currency, for different payment vehicles, payment frequencies and payment durations.

4. To standardise estimates into one currency, local currencies were converted to US dollars. Exchange rates ${ }^{3}$ for 2006 were obtained for each currency reported from Penn World Table 8.0 (Feenstra et al., 2013).

5. The WTP in terms of perpetual payment per kWh of electricity consumption in 2006 US dollars was then derived using Equation 1.

$$
\text { WTPAP06 }=(\text { PAPL06/HHEC }) *(C P I 06 / \text { USDER06 })
$$

where,

WTPAP06 = Willingness-to-pay in perpetuity for one kWh of electricity consumption expressed in 2006 US dollar;

PAPL06 = Perpetual payment for total annual electricity consumption in 2006 expressed in local currency;

HHEC = Average amount of household electricity consumption (kWh) in the study area/region or country for the study year;

CPI06 = Consumer Price Index for a given country or state for the year 2006;

USDER06 = Exchange rate of a local currency to the US dollar in 2006.

\footnotetext{
${ }^{3}$ Purchasing power parity (PPP) was also been used to convert local currencies. The significance of parameters, magnitude of effects, and subsequent conclusions from regressions when using PPP are not significantly different from results using exchange rates as shown in this paper. Results that used PPP to convert local currencies are available upon request.
} 


\section{Choice of moderator variables}

The 29 studies varied widely in the energy-related characteristics analysed (e.g. energy mix, level of RE, location/site of energy generation), the characteristics of the survey used to obtain responses (e.g. elicitation format, administration procedure, sample characteristics, $\mathrm{CV}$ or $\mathrm{CE}$ ), and the approaches taken to model these responses (e.g. type of econometric models, specification of the models). In a meta-regression, it is necessary to choose moderator variables that can: (1) measure the true differences between effect sizes across population and time; (2) account for the differences in design, elicitation and administration of the primary studies; and, (3) account for the explainable variability that is due to different model specification or even misspecification in the primary studies. The moderator variables we used in our meta-regression analysis of WTP for RE sources are described in this section and in Table 2.

A number of variables were included to measure true differences between effect sizes. A variable was included to control for potential income effects because a wealthier population might have a higher WTP than a poorer population. Where available, we used the sample mean annual household income for this purpose, otherwise, we used national mean household income.

WTP is expected to depend on current consumption levels. The primary studies typically did not report current household electricity consumption levels. We therefore collected information on national or regional mean household consumption levels to control for this potential effect. Using national or regional mean income and consumption levels is justified to some extent on the basis that survey samples generally claimed to be representative of the population. Ten out of 22 studies can be viewed as nationally representative, and so we used national mean consumption data. The others are regional studies. We were able to obtain regional mean consumption data for nine regional studies conducted in US, Australia, South Korea and Scotland. We used national mean consumption data for the remaining regional studies.

Respondents' WTP may also depend on the share of RE in the proposed portfolio. Not all studies reported the proportion of electricity to be replaced by renewable sources. However, all studies were conducted under a national or regional policy background. For example, Italy aims to achieve an energy portfolio with 22 per cent electricity generated from renewable sources (Bollino, 2009). In cases where the share of RE was not specified in the primary 
study's WTP question, we assumed that the implicit share would be the proposed national or regional target. We further controlled for the fact that the current share of RE in a country's total energy consumption varies between countries, by including this share as a variable in our analysis.

WTP values also need to be specified for different types of RE sources. People may have a different WTP for RE sources due to higher awareness of one source over another, or due to negative perceptions toward a certain type of RE. We controlled for this by including the type of RE specified in the WTP questions in our analysis. Also, WTP can change over time and under different political climates. Thus, the study (survey) year was included in the analysis to capture this effect.

Finally, we included moderator variables to account for differences in design, elicitation and administration of the primary studies. Variables that were included related to the way in which the survey was administered (mail, online, phone, etc.), whether the survey was piloted, and whether an 'opt-out' option was included in the WTP questions. With respect to the latter, we assumed that an opt-out option was implicit in all CV studies, since respondents can give a zero WTP or say 'no' to the discrete choice question. The CE studies all explicitly specified whether an opt-out option was included in their survey. We also differentiate whether RE was presented as an independent policy, or as part of a policy package. If RE is a component of a policy package, it will be difficult to disentangle whether respondents vote for renewable energy and/or for the other components in the package. It follows that WTP may be greater when the RE is presented as an independent policy.

We also included moderator variables to measure the difference between models of different specifications, shown in Table 2. We created a number of dummy variables to indicate whether the model specification included education attainment, age, income level, prior knowledge about RE, ownership of the property, gender, employment status, general environmental attitudes and additional household characteristics. We collected a number of other variables that described survey design and model specification, but these were dropped from the final regression analysis ${ }^{4}$ either because they only differentiated one or two studies from the remainder, or because they were highly correlated with other included variables.

\footnotetext{
${ }^{4}$ We do not report summary statistics for these dropped variables but full information is available from the authors upon request.
} 


\section{Model selection and weights}

Nelson and Kennedy (2009) provide a thorough review of the use of meta-analysis in environmental and resource economics. They recommend a number of best practices, including weighting the moderator variables by the inverse of the standard errors of the estimates from primary studies. However, in many of the primary studies we found, standard errors (or equivalent statistics) were not provided. Only 99 out of a total of 142 observations provided sufficient information to obtain the standard errors for WTP values. Some studies provided standard errors for the parameters in the estimated utility function. However, without knowledge about the covariance, we are unable to retrieve the correct standard errors for WTP values because these estimates rely on using the Delta method. Stanley and Rosenberger (2009) argue that where the effect size of the meta-analysis is a nonlinear function of the estimated parameters in the primary studies, the square root of the sample size should be used instead of the standard errors because the standard errors and the dependent variable are jointly determined. In our case, the WTP values are nonlinear functions of the regression parameters. Therefore, we used the square root of the sample size to weight the moderator variables.

In a study of ordinary least squares, weighted least squares (WLS) and mixed effects estimators of meta-regression analysis, Koetse et al (2010) found that fixed effects WLS was most robust in the presence of potentially omitted variables. Therefore, we first estimated fixed-effects WLS for the full sample ( $\mathrm{n}=142$ ) with standard errors clustered by primary study. Fixed-effects meta-regression assumes that all the heterogeneity can be explained by the moderator variables and may lead to excessive type I errors if there is unexplained heterogeneity (Thompson and Sharp, 1999; Higgins and Thompson, 2004). To account for possible unexplained between-study heterogeneity, we also estimated mixed-effects metaregressions.

\section{Publication bias}

A well-known issue with meta-analysis is publication bias. Journals, or authors, often select publications that have statistically significant results. Another type of publication bias arises from censoring theoretically inconsistent or conceptually unexpected values of the effect in question. Such practices mean that any tally of published studies, like meta-analysis, may be biased and potentially misleading (Stanley, 2005). In the WTP literature, we expect that 
researchers do not necessarily select significant results only, because the true WTP may well be zero. Being unable to reject the null hypothesis is not necessarily a problem.

Regarding data censoring, it is generally expected that WTP will be positive due to, for example, a warm glow effect of supporting RE sources. However, WTP values could be negative depending on respondents' opinion about the type of energy in a given location and time (e.g. negative WTP for using biomass or hydro power). If such negative WTP values are censored from the literature, publication bias could result.

Publication bias can be identified by visual exploration and by performing formal statistical tests including rank correlation test and regression-based asymmetry and precision tests (e.g. Begg and Mazumdar, 1994; Egger et al., 1997; Stanley, 2008). The Begg’s test evaluates the significance of the Kendall's rank correlation between the standardized effect sizes and their variances. A significant correlation is interpreted as providing strong evidence of publication bias. Egger et al. (1997) proposed a regression-based test that evaluates whether the intercept deviates significantly from zero in a regression of standardized effect sizes against their precision (Egger et al., 1997; Stanley, 2008). A significant deviation is indicative of publication bias. However, with small samples, these tests are expected to have only moderate power at best (Steichen et al., 1998; Stanley 2008). On the one hand, the tests may be too liberal with false-positive claims of asymmetry and publication bias that translate into conservativeness at the meta-analysis level. On the other hand, insignificant test results cannot rule out the possibility of publication bias.

Begg and Berlin (1988) suggested that publication bias will be proportional to the inverse of the square root of sample size. Following Stanley (2008), we therefore controlled for publication bias by including the inverse of the square root of sample size as a variable in the meta-regression analysis. By doing this, one must interpret the intercept in the regression as an estimate of the WTP value for a study with an infinite sample size.

\section{Results}

\section{Exploratory meta-analysis}

Table 2 presents the summary statistics for the 29 primary studies that were suitable for our meta-regression analysis. The studies had been conducted in 14 countries, with most coming from the United States. There is a clear dominance of primary studies from OECD countries (27 out of 29). 
The higher number of studies conducted in recent years indicates a growing interest in measuring people's WTP for RE. There was a reasonable level of variation in the distribution of journals that publish these studies, with Energy Policy being the dominant one.

The average sample size in the primary studies was 641, with samples as large as 2,864 (Byrnes et al., 1999) and as small as 35 respondents (Odam, 2011). The number of observations can be very different from the sample size (number of respondents), especially if the study employed a choice experiment where there are typically multiple observations per respondent. The average number of modelled observations was 1,275, ranging from 23 (Kontogianni et al., 2013) to 7,566 (Kosenius and Ollikainen, 2013).

The primary studies yielded a total of 142 WTP estimates. These WTP estimates and their associated 95\% confidence intervals are sorted from smallest to largest point-estimate in Figures 1 and 2. The mean WTP for RE was 1.5 cents per kWh. The range of estimates was wide: from -39.6 cents/kWh as the lowest negative WTP, to 16.9 cents/kWh as the highest positive WTP. The majority of WTP values fell between -10 and +10 cents/kWh (Figure 1 , bars indicate the $95 \%$ confidence intervals).

There seems to be a reporting bias in our data. A substantial proportion of the observations (43 out of 142) did not report the standard errors (or equivalent statistics) of the point estimates of WTP, especially when the point estimates were close to zero.

\section{Publication Bias}

To allow a more detailed exploration of the statistical significance of WTP estimates, we plotted a truncated sub-sample in Figure 2. The WTP estimates greater than 10 cents/kWh or less than negative 10 cents/kWh were excluded from this sub-sample. There were significant as well as insignificant WTP estimates (i.e. confidence bars crossing horizontal axis). Thus, a publication bias towards only statistically significant and positive values does not appear to be a serious problem. Table 3 presents results from Begg's adjusted rank correlation test and Egger's regression asymmetry test on the subset of observations ( $n=99)$ that reported standard errors or equivalent statistics. The results from Begg's test provide no evidence for publication bias; however, the Egger's test is strongly suggestive of publication bias. The visual exploration of the full sample and the formal tests on the subset of data provide no conclusive evidence for publication bias. 
Table 2 - Definition of variables and summary statistics.

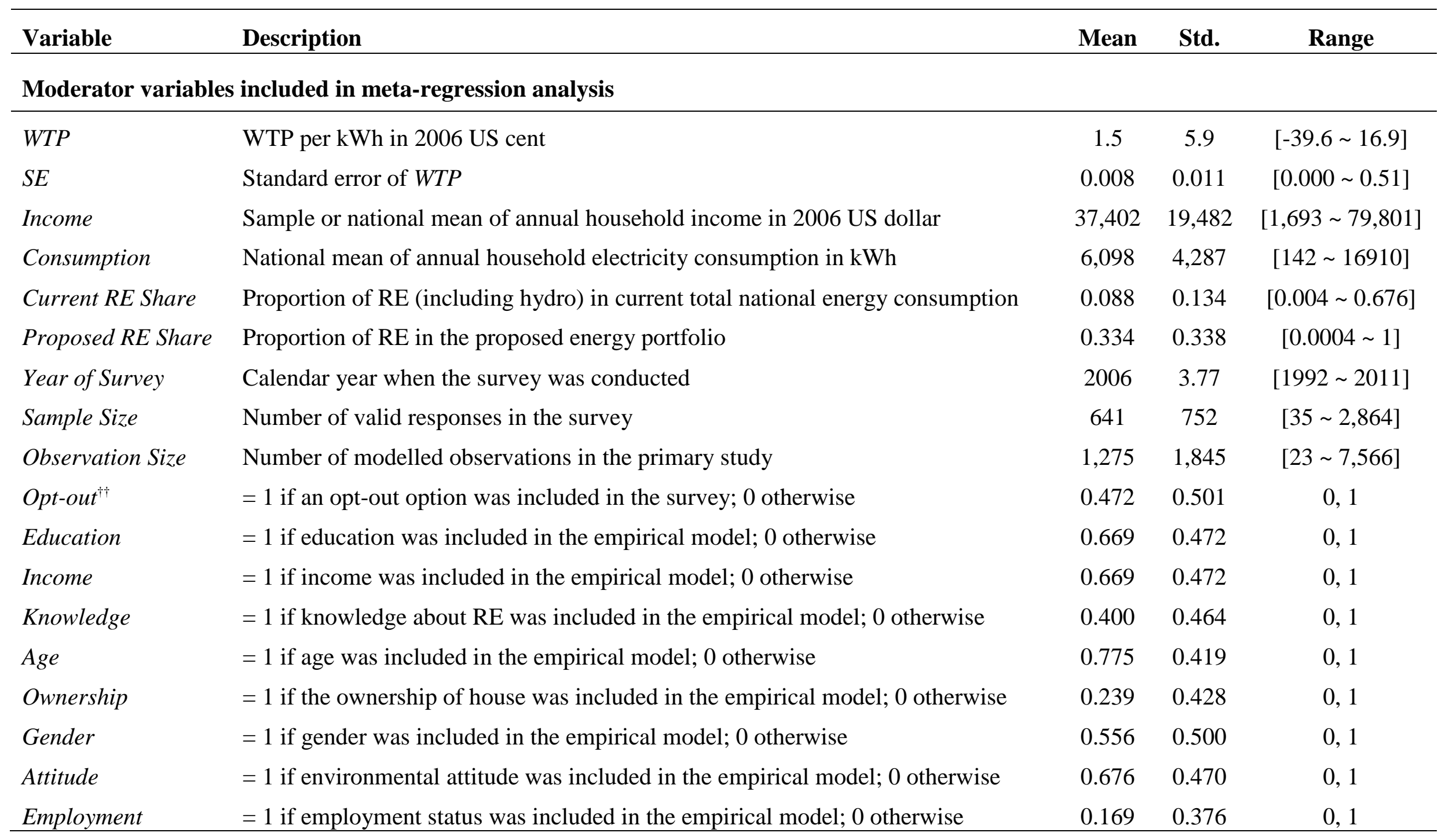


Table 2 (cont.) - Definition of variables and summary statistics

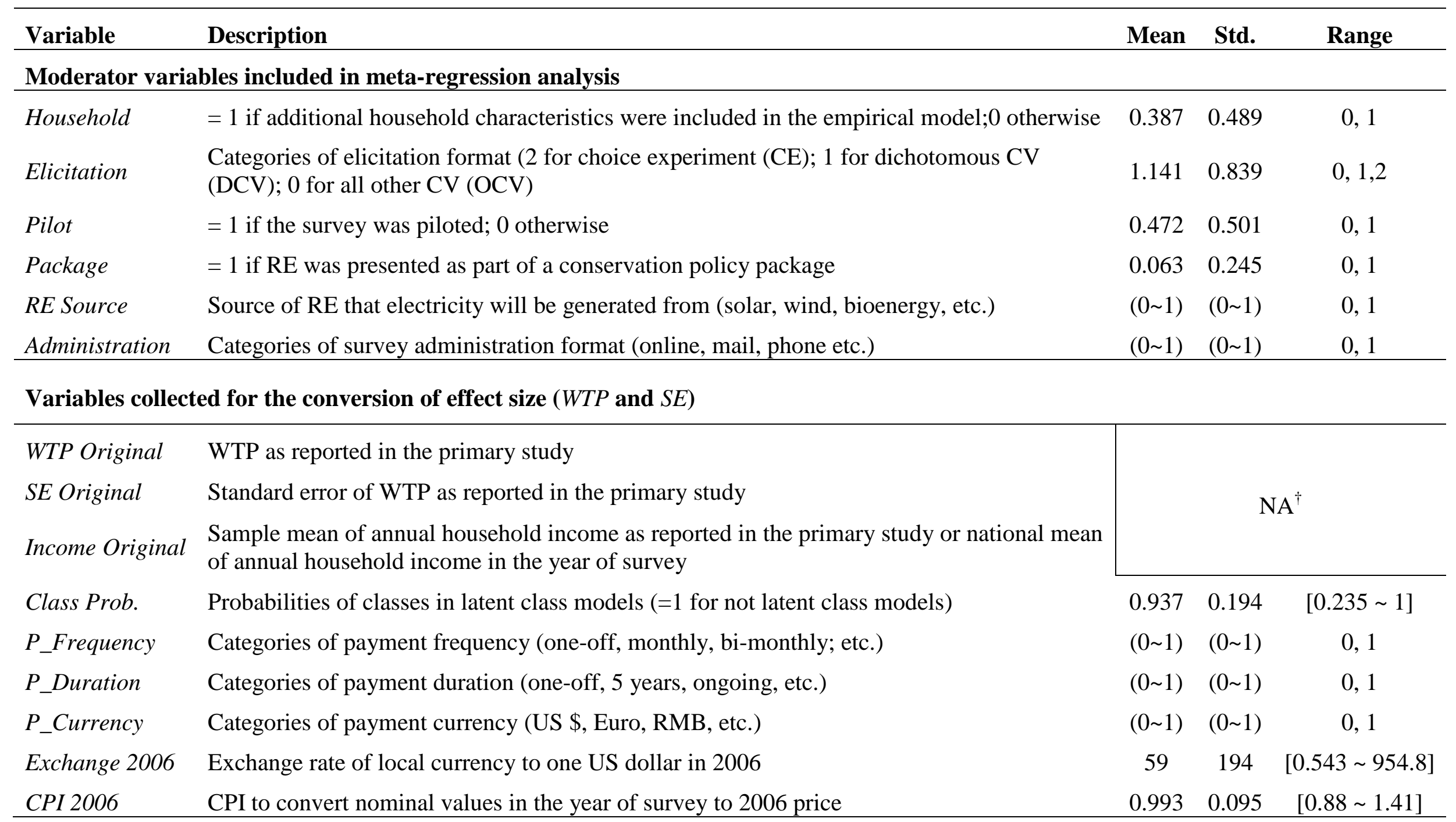

${ }^{\dagger}$ Variables are expressed as nominal values in different currencies; ${ }^{\dagger \dagger}$ All CV studies are assumed to have an opt-out option (i.e. not accepting the offered bid amount). 


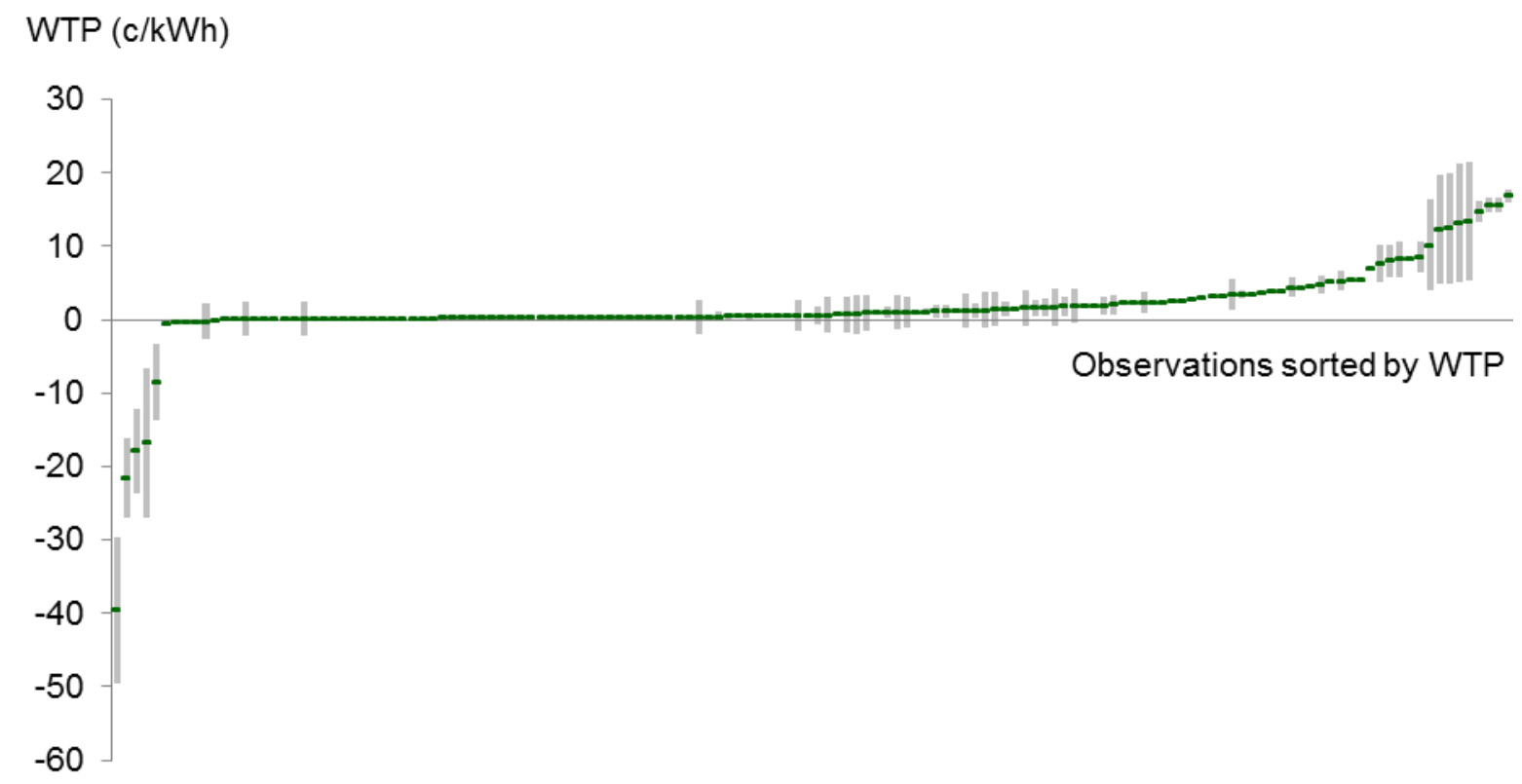

Figure 1 - WTP point estimates and their 95\% confidence intervals (full sample).

Note: 43 observations out of the full sample ( $\mathrm{n}=142$ ) did not report standard errors or equivalent statistics.

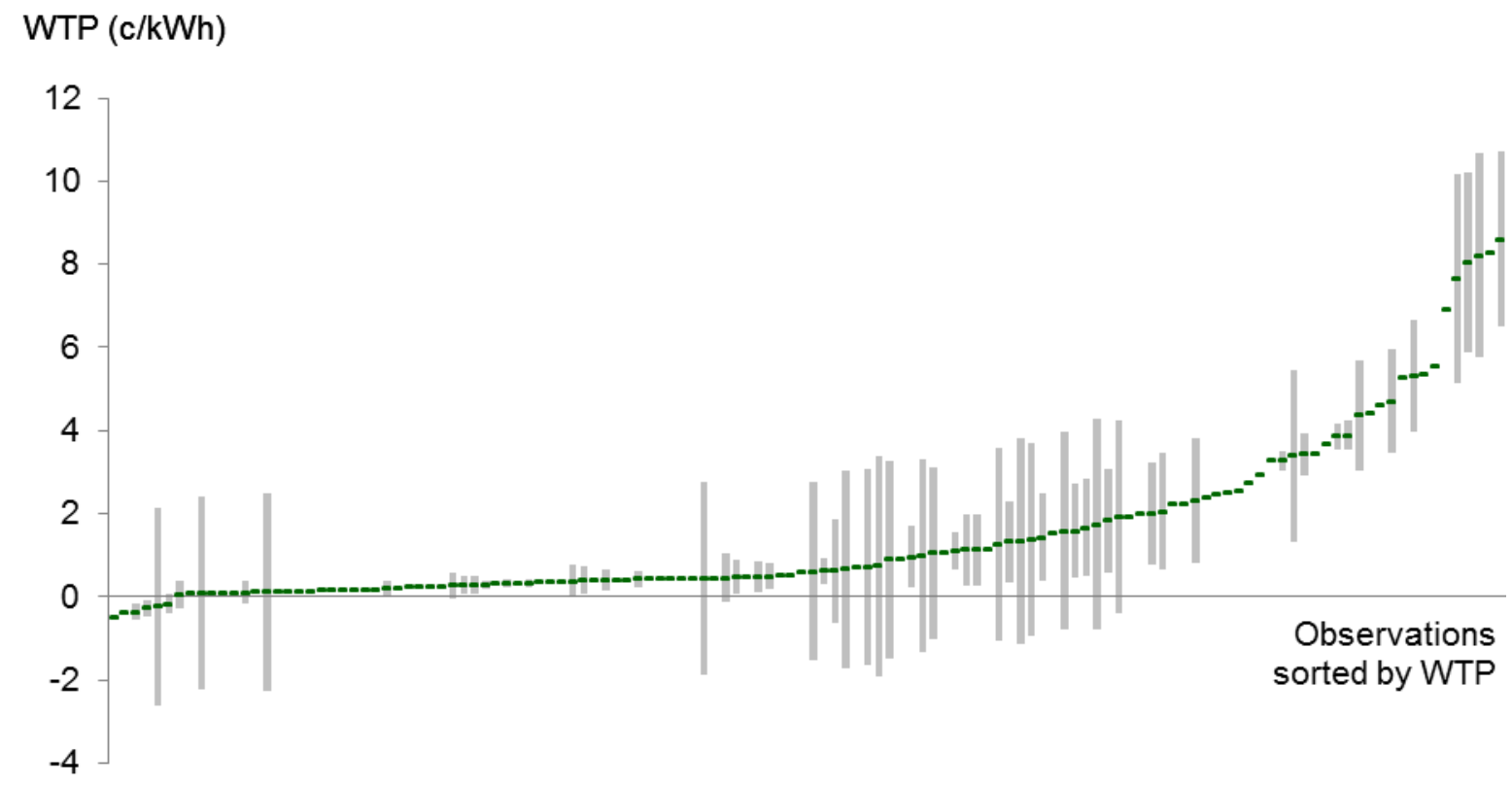

Figure 2 - WTP point estimates and their 95\% confidence intervals (truncated sample).

Note: 42 observations out of truncated sample $(n=128)$ did not report standard errors or equivalent statistics. 
Table 3 - Egger's test and Begg's test for publication bias

\begin{tabular}{lllll}
\hline Egger's Test & Coefficient & t-statistic & Begg's Test & \\
\hline Slope & $0.003^{* *}$ & 20.21 & Adj.Kendall's Score & $949^{* *}$ \\
Bias & 1.237 & 1.06 & z Stat. & 2.87 \\
\hline Number of observations & 99 & & \\
\hline
\end{tabular}

Meta-regression analysis

Table 4 presents estimation results of fixed-effects and mixed-effects meta-regression models. Models S1 to S4 used the square root of the sample size as weights for the moderator variables, and the inverse of the square root of the sample size to control for possible publication bias. Models S5 to S8 used the square root of the number of observations as weights for the moderator variables, and the inverse of the square root of number of observations to control for possible publication bias. Models S1 and S5 were estimated using the full sample including all negative and positive WTP values. Models S2 and S6 used a subset of the sample excluding four negative outliers which come from two primary studies (Odam, 2011; Cicia et al., 2012). Models S3, S4, S7 and S8 also excluded these outliers and used natural log transformed WTP as the dependent variable. Models S1 to S3 and S4 to S6 are fixed-effects WLS regressions. Models S4 and S8 are the mixed-effects meta-regression with between-study variance $\left(\tau^{2}\right)$ estimated by the residual maximum likelihood (REML). Results from the models S1 and S5 differed substantially from those of the models where outliers were removed from the sample (S2, S3, S4, S6, S7, S8). The $\mathrm{R}^{2}$ statistics of the latter models significantly improved by removing the outliers, and further improved by log transforming the dependent variable (models S3 and S7). The $I_{\text {res }}^{2}$ statistic in Models S4 and S8 indicates the percentage of the residual variation that is attributable to between-study heterogeneity, as opposed to within-study sampling variability. In both models, almost all of the residual variation is due to between-study heterogeneity, strongly suggesting the use of mixed-effects models. In the following discussion we focus on the results of the model S4 unless stated otherwise.

The coefficient of the inverse of the square root of the sample size (or the number of observations) and the constant term are tests for precision effect and publication bias, respectively. Neither is significant. The insignificant constant term suggests that there is no 
evidence of significant publication bias. This is consistent with our visual illustration in Figures 1 and 2, and tests presented in Table 3.

The context and background under which the primary studies were conducted had a significant impact. The WTP for RE was positively associated with the RE penetration in the current energy consumption and the RE penetration in the proposed energy portfolio, and negatively associated with the current household electricity consumption level.

The source of RE affected respondents' WTP. People were willing to pay more for the electricity generated from solar, wind or generic RE (i.e. no indication of specific source) than biomass, as indicated by the positive and statistically significant values of the "Solar", "Wind” and “Generic RE” dummies.

Survey administration also had an impact on the effect size. Online surveys (i.e. the default in our model) and face-to-face surveys tended to generate lower WTP values for RE. Contingent valuation studies that elicited dichotomous responses produced significantly higher WTP estimates than those using open-ended, payment card and other question formats. This finding is consistent with previous literature (Boyle et al., 1996; Welsh and Poe, 1998). We also found that surveys using choice experiments produced significantly higher WTP estimates than studies using contingent valuation (a test of equality between the coefficient of DCV and that of CE was rejected at $1 \%, F(1,102)=21.24)$. The WTP for RE also depended on the specification used in the empirical models. The set of social, economic and demographic variables included in the model specifications significantly influenced the WTP estimates (particularly if education, income and additional household characteristics were included). 
Table 4 - Fixed-Effects and Mixed-Effects Meta-Regression Results

\begin{tabular}{|c|c|c|c|c|c|c|c|c|}
\hline \multirow{2}{*}{ Dependent Variable: } & \multicolumn{2}{|c|}{$\mathrm{S1}^{\dagger}: \mathrm{WTP}$} & \multicolumn{2}{|c|}{$\mathrm{S}^{\dagger}: \mathrm{WTP}$} & \multicolumn{2}{|c|}{$\mathrm{S}^{\dagger}: \log (\mathrm{WTP})$} & \multicolumn{2}{|c|}{$S 4^{\ddagger}: \log (\mathrm{WTP})$} \\
\hline & Coef. & t-stat. & Coef. & t-stat. & Coef. & t-stat. & Coef. & t-stat. \\
\hline $\begin{array}{l}\text { 1/SQRT(sample size) } \\
\text { Context }\end{array}$ & -49.98 & -1.24 & 6.95 & 0.84 & 5.27 & 1.39 & 4.40 & 1.19 \\
\hline Log (Income) & -0.01 & -0.01 & 0.50 & 0.98 & 0.31 & 1.43 & 0.39 & 1.59 \\
\hline Log (Consumption) & -1.42 & -1.90 & $-2.54 * *$ & -5.17 & -0.88 & -3.53 & $-1.04 * *$ & -4.08 \\
\hline Current RE Share & $13.79 *$ & 2.58 & $4.08 *$ & 2.17 & 2.97 & 3.36 & $2.72 *$ & 2.19 \\
\hline Proposed RE Share & 0.27 & 0.20 & $2.44^{* *}$ & 3.48 & 1.28 & 4.14 & $1.17^{* *}$ & 4.33 \\
\hline Year & $-0.19 * *$ & -2.94 & -0.04 & -0.74 & -0.05 & -2.07 & -0.03 & -1.04 \\
\hline RE Source & & & & & & & & \\
\hline Solar & 2.30 & 1.08 & 1.55 & 1.57 & $0.66^{*}$ & 2.54 & $0.67 * *$ & 2.69 \\
\hline Wind & 2.04 & 1.09 & 1.10 & 1.34 & 0.53 & 1.92 & $0.52 *$ & 2.22 \\
\hline Hydro & 1.53 & 0.90 & 0.49 & 0.65 & 0.55 & 1.25 & 0.61 & 1.66 \\
\hline Generic $R E$ & 2.13 & 1.48 & 1.36 & 1.97 & $0.99 * *$ & 4.52 & $0.92 * *$ & 3.72 \\
\hline Survey Administratio & & & & & & & & \\
\hline Mail & 5.70 & 1.27 & $3.68 * *$ & 4.43 & $2.86^{* *}$ & 4.93 & $2.89 * *$ & 5.25 \\
\hline Face-to-Face & 3.56 & 1.29 & 0.30 & 0.45 & 0.52 & 1.37 & 0.35 & 0.75 \\
\hline Phone & 5.00 & 1.30 & $3.23^{* *}$ & 3.58 & $2.74 * *$ & 4.17 & $2.31 * *$ & 3.57 \\
\hline Other & 3.24 & 1.71 & $3.74 * *$ & 3.99 & $2.39 * *$ & 5.29 & $2.88 * *$ & 5.14 \\
\hline Survey Design & & & & & & & & \\
\hline Package & 5.82 & 1.64 & -0.47 & -0.32 & 0.21 & 0.31 & -0.28 & -0.34 \\
\hline Pilot & -1.21 & -1.45 & 0.29 & 0.53 & 0.18 & 0.81 & 0.27 & 1.12 \\
\hline Opt-out & 3.00 & 1.70 & -0.60 & -1.02 & -0.03 & -0.10 & -0.14 & -0.48 \\
\hline Elicitation $=1(D C V)$ & -2.44 & -0.89 & $1.51 *$ & 2.25 & $1.19 * *$ & 3.53 & $1.27 * *$ & 3.46 \\
\hline Elicitation $=2(\mathrm{CE})$ & 0.46 & 0.29 & $4.72^{* *}$ & 6.26 & $3.06 * *$ & 8.47 & $3.22 * *$ & 5.85 \\
\hline
\end{tabular}

Notes: $*$ and $* *$ indicate statistical significance at $5 \%$ and $1 \%$ levels. $†$ Fixed effects WLS models. $\ddagger$ Mixedeffect models. 
Table 4 (cont.) - Fixed-Effects and Mixed-Effects Meta-Regression Results

\begin{tabular}{|c|c|c|c|c|c|c|c|c|}
\hline \multirow{2}{*}{ Dependent Variable: } & \multicolumn{2}{|c|}{ S1 ${ }^{\dagger}:$ WTP } & \multicolumn{2}{|c|}{$\mathrm{S}^{\dagger}: \mathrm{WTP}$} & \multicolumn{2}{|c|}{$\mathrm{S}^{\dagger}: \log (\mathrm{WTP})$} & \multicolumn{2}{|c|}{ S4 $4^{\ddagger} \log (\mathrm{WTP})$} \\
\hline & Coef. & t-stat. & Coef. & t-stat. & Coef. & t-stat. & Coef. & t-stat. \\
\hline \multicolumn{9}{|l|}{ Model Specification } \\
\hline Education & -0.71 & -0.68 & $-1.42^{*}$ & -2.67 & $-1.01 * *$ & -4.29 & $-1.11^{* *}$ & -3.73 \\
\hline Income & 1.98 & 1.36 & $1.31 *$ & 2.64 & $1.07 * *$ & 4.81 & $0.90 * *$ & 2.75 \\
\hline Knowledge & $-2.82 * *$ & -5.88 & -0.08 & -0.17 & 0.03 & 0.14 & 0.04 & 0.11 \\
\hline Age & $2.16^{*}$ & 2.13 & $1.39 * *$ & 2.88 & 0.18 & 0.74 & 0.30 & 0.87 \\
\hline Ownership & 0.32 & 0.18 & -0.62 & -0.93 & -0.09 & -0.30 & -0.25 & -0.66 \\
\hline Gender & $-3.14^{*}$ & -2.20 & -0.39 & -0.62 & 0.14 & 0.53 & 0.21 & 0.74 \\
\hline Attitude & 1.61 & 1.51 & -0.08 & -0.16 & 0.13 & 0.61 & 0.18 & 0.56 \\
\hline Employment & 2.23 & 0.54 & -0.53 & 0.73 & 0.13 & 0.37 & -0.09 & -0.20 \\
\hline Household & $2.99 * *$ & 5.03 & $2.17^{* *}$ & 5.35 & $1.92^{* *}$ & 10.58 & $1.92^{* *}$ & 6.40 \\
\hline Constant & 10.17 & 1.66 & $11.44^{*}$ & 2.76 & -0.70 & -0.47 & -0.27 & -0.13 \\
\hline Observations & \multicolumn{2}{|c|}{142} & \multicolumn{2}{|c|}{138} & \multicolumn{2}{|c|}{131} & \multicolumn{2}{|c|}{131} \\
\hline $\mathrm{R}^{2}$ & \multirow{3}{*}{\multicolumn{2}{|c|}{0.45}} & \multirow{3}{*}{\multicolumn{2}{|c|}{0.66}} & \multirow{3}{*}{\multicolumn{2}{|c|}{0.84}} & \multicolumn{2}{|c|}{0.79} \\
\hline$\tau^{2}$ & & & & & & & \multicolumn{2}{|c|}{0.42} \\
\hline$I_{\text {res }}^{2}$ & & & & & & & \multicolumn{2}{|c|}{$99.52 \%$} \\
\hline
\end{tabular}

Notes: ${ }^{*}$ and $* *$ indicate statistical significance at $5 \%$ and $1 \%$ levels. ${ }^{\dagger}$ Fixed effects WLS models. ${ }^{\ddagger}$ Mixedeffect models. 
Table 4 (cont.) - Fixed-Effects and Mixed-Effects Meta-Regression Results.

\begin{tabular}{|c|c|c|c|c|c|c|c|c|}
\hline \multirow{2}{*}{ Dependent Variable: } & \multicolumn{2}{|c|}{$\mathrm{S}^{\dagger}: \mathrm{WTP}$} & \multicolumn{2}{|c|}{$\mathrm{S6}^{\dagger}:$ WTP } & \multicolumn{2}{|c|}{$S 7^{\dagger}: \log (\mathrm{WTP})$} & \multicolumn{2}{|c|}{$\mathrm{SB}^{\ddagger}: \log (\mathrm{WTP})$} \\
\hline & Coef. & t-stat. & Coef. & t-stat. & Coef. & t-stat. & Coef. & t-stat. \\
\hline $\begin{array}{l}\text { 1/SQRT (number of } \\
\text { Obs.) }\end{array}$ & -57.82 & -1.03 & $16.48 *$ & 2.45 & 5.44 & 1.46 & 3.45 & 0.94 \\
\hline Context & & & & & & & & \\
\hline $\log$ (Income) & 0.15 & 0.53 & 0.36 & 0.85 & 0.24 & 1.57 & 0.38 & 1.55 \\
\hline Log (Consumption) & -1.35 & -1.59 & $-2.29 * *$ & -5.44 & $-0.75^{* *}$ & -3.54 & $-1.00 * *$ & -3.97 \\
\hline Current RE Share & $12.24 *$ & 2.1 & $3.62 *$ & 2.46 & $2.75^{* *}$ & 3.71 & $3.13^{* *}$ & 2.67 \\
\hline Proposed RE Share & 0.45 & 0.25 & $2.95 * *$ & 4.12 & $1.42^{* *}$ & 4.73 & $1.18^{* *}$ & 4.23 \\
\hline Year & -0.11 & -0.91 & -0.09 & -1.55 & -0.05 & -1.76 & -0.04 & -1.19 \\
\hline \multicolumn{9}{|l|}{ RE Source } \\
\hline Solar & 2.42 & 1.14 & 1.63 & 1.67 & $0.73^{* *}$ & 2.94 & $0.68 * *$ & 2.72 \\
\hline Wind & 2.10 & 1.18 & 1.13 & 1.43 & $0.62 *$ & 2.58 & $0.53 *$ & 2.29 \\
\hline Hydro & 1.19 & 0.75 & 0.04 & 0.06 & 0.16 & 0.60 & 0.53 & 1.39 \\
\hline Generic RE & 1.65 & 1.1 & $1.58^{*}$ & 2.30 & $0.98 * *$ & 5.53 & $0.97 * *$ & 3.81 \\
\hline \multicolumn{9}{|l|}{ Survey Administration } \\
\hline Mail & 8.36 & 1.29 & $3.19 * *$ & 4.04 & $2.94 * *$ & 5.46 & $2.99 * *$ & 5.50 \\
\hline Face-to-Face & 5.07 & 1.21 & -0.20 & -0.30 & 0.40 & 1.09 & 0.36 & 0.74 \\
\hline Phone & 6.70 & 1.3 & $2.63^{* *}$ & 3.03 & $2.45^{* *}$ & 3.49 & $2.3 * *$ & 3.51 \\
\hline Other & 4.26 & 1.42 & $3.03 * *$ & 3.50 & $2.31 * *$ & 4.70 & $2.87 * *$ & 4.99 \\
\hline \multicolumn{9}{|l|}{ Survey Design } \\
\hline Package & 7.81 & 1.37 & -0.26 & -0.22 & 0.12 & 0.19 & -0.20 & -0.24 \\
\hline Pilot & -0.44 & -0.42 & 0.25 & 0.48 & 0.28 & 1.65 & 0.31 & 1.29 \\
\hline Opt-out & 1.89 & 1.36 & -0.46 & -1.02 & 0.02 & 0.07 & 0 & -0.01 \\
\hline Elicitation $=1$ & -2.51 & -0.76 & $2.32 * *$ & 4.63 & $1.31^{* *}$ & 4.38 & $1.20 * *$ & 3.29 \\
\hline Elicitation $=2$ & -1.57 & -0.35 & $6.01 * *$ & 6.81 & $3.35^{* *}$ & 7.73 & $3.33^{* *}$ & 5.36 \\
\hline
\end{tabular}

Notes: $*$ and ${ }^{* *}$ indicate statistical significance at $5 \%$ and $1 \%$ levels. ${ }^{\dagger}$ Fixed effects WLS models. ${ }^{\ddagger}$ Mixedeffect models. 
Table 4 (cont.) - Fixed-Effects and Mixed-Effects Meta-Regression Results.

\begin{tabular}{|c|c|c|c|c|c|c|c|c|}
\hline \multirow{2}{*}{ Dependent Variable: } & \multicolumn{2}{|c|}{$\mathrm{S}^{\dagger}: \mathrm{WTP}$} & \multicolumn{2}{|c|}{$\mathrm{S6}^{\dagger}: \mathrm{WTP}$} & \multicolumn{2}{|c|}{$S 7^{\dagger}: \log (\mathrm{WTP})$} & \multicolumn{2}{|c|}{ S8 ${ }^{\ddagger}: \log (\mathrm{WTP})$} \\
\hline & Coef. & t-stat. & Coef. & t-stat. & Coef. & t-stat. & Coef. & t-stat. \\
\hline \multicolumn{9}{|l|}{ Model Specification } \\
\hline Education & -0.37 & -0.49 & $-1.43^{* *}$ & -3.18 & $-1.12 * *$ & -6.33 & $-1.19 * *$ & -4.03 \\
\hline Income & 2.34 & 1.49 & $1.32 * *$ & 3.44 & $1.09 * *$ & 4.17 & $0.96^{* *}$ & 2.92 \\
\hline Knowledge & $-2.88 *$ & -2.10 & 0.54 & 1.19 & 0.20 & 0.84 & 0.06 & 0.18 \\
\hline Age & 2.01 & 1.5 & $1.63^{* *}$ & 3.41 & 0.42 & 1.62 & 0.42 & 1.27 \\
\hline Ownership & 0.45 & 0.24 & -0.11 & -0.17 & 0.04 & 0.11 & -0.11 & -0.30 \\
\hline Gender & -2.35 & -1.48 & -0.40 & -0.78 & 0.08 & 0.37 & 0.09 & 0.35 \\
\hline Attitude & 1.59 & 0.99 & -0.08 & -0.18 & 0.14 & 0.71 & 0.24 & 0.76 \\
\hline Employment & 1.80 & 0.73 & -0.23 & -0.31 & 0.21 & 0.53 & 0.04 & 0.09 \\
\hline Household & $3.73 * *$ & 3.21 & $2.00 * *$ & 4.41 & $1.95^{* *}$ & 10.66 & $1.90 * *$ & 6.17 \\
\hline Constant & 5.25 & 0.57 & $9.98 *$ & 2.54 & -1.54 & -0.96 & -0.63 & -0.29 \\
\hline Observations & \multicolumn{2}{|l|}{142} & \multicolumn{2}{|c|}{138} & \multicolumn{2}{|c|}{131} & \multicolumn{2}{|c|}{131} \\
\hline $\mathrm{R}^{2}$ & \multirow{3}{*}{\multicolumn{2}{|c|}{0.39}} & \multirow{3}{*}{\multicolumn{2}{|c|}{0.62}} & \multirow{3}{*}{\multicolumn{2}{|c|}{0.85}} & \multicolumn{2}{|c|}{0.79} \\
\hline$\tau^{2}$ & & & & & & & \multicolumn{2}{|c|}{0.42} \\
\hline$I_{\text {res }}^{2}$ & & & & & & & \multicolumn{2}{|c|}{$99.69 \%$} \\
\hline
\end{tabular}

Note: ${ }^{*}$ and $* *$ indicate statistical significance at $5 \%$ and $1 \%$ levels. ${ }^{\dagger}$ Fixed effects WLS models. ${ }^{\ddagger}$ Mixed-effect models. 
1 Table 5 presents marginal effects on estimated WTP for variables that have statistically

2 significant impacts based on Model S4. Differences in survey administration and design have

3 large marginal effects. Context variables and RE source, which explain the true differences

4 between effect sizes across the population, have much smaller marginal impacts in general.

5

6 Table 5 - Marginal effects on willingness-to-pay for renewable energy.

\begin{tabular}{lll}
\hline Variables & Marginal Changes & $\begin{array}{c}\text { Marginal Effects on } \\
\text { WTP }^{\dagger} \text { (cent/kWh) }\end{array}$ \\
\hline Log (consumption) & 10\% increase in consumption & -0.10 \\
Current RE Share & Increase from 0\% to 10\% & 0.27 \\
Proposed RE Share & Increase from 0\% to 10\% & 0.12 \\
Solar & From biomass to solar & 0.67 \\
Wind & From biomass to wind & 0.52 \\
Generic RE & From biomass to generic RE & 0.92 \\
Mail & From online to mail & 2.89 \\
Phone & From online to phone & 2.31 \\
Dichotomous CV & From 0 to 1 & 1.27 \\
Choice Experiment & From 0 to 1 & 3.22 \\
Education & From 0 to 1 & -1.11 \\
Income & From 0 to 1 & 0.90 \\
Household & From 0 to 1 & 2.55 \\
\hline
\end{tabular}

$7 \quad{ }^{\dagger}$ Marginal effects evaluated at sample mean.

8

\section{5. Discussion}

10 Since the Kyoto Protocol entered into force in 2005, many developed countries have actioned

11 policies to reduce greenhouse gas emissions to meet their emissions reduction targets. One of

12 the ways in which countries meet their reduction commitments is to increase the share of

13 renewable energy (RE) use. Consequently, there has been increased government and business 
interest in household adoption of RE which has resulted in an increased number of scientific publications that evaluate public willingness-to-pay (WTP) for RE.

We found that WTP for RE (in cents/kWh) is more sensitive to the design and modelling features of the study, than to other factors affecting WTP (Table 4). This insight also differentiates our study from Sundt and Rehdanz (2014). If WTP estimates are primarily dependent on the study design and estimation models used, one might question the validity of estimates, which calls for caution interpreting the WTP estimates in the primary studies. It also has profound implications for policy suggestions drawn upon such studies and for value transfer applications. The dependent variable in our meta-regression analysis, WTP in cents/kWh of RE (Section 2, equation 1), was calculated by dividing household WTP by the average $\mathrm{kWh}$ consumed per household. It is possible that some respondents considered their total electricity bill, rather than their actual energy consumption when answering the WTP questions. In that case, WTP will be less sensitive to the amount of energy (in kWh) consumed. To test whether consumers base their response on their annual electricity bill or their actual energy consumption, future stated preference studies should explicitly state: (1) the proportion of RE (in $\mathrm{kWh}$ ) to replace non-renewable energy, and (2) how this increased share of RE affects the household's total electricity bill. In most stated preference studies, only one of these two variables is used. Both specifications would be necessary for the respondent to provide an informed reply to the WTP question - taking their budget constraint into account, and the premium they would be willing to pay for renewable energy as opposed to non-renewables. ${ }^{5}$ Notwithstanding the above, when we control for survey design, elicitation format, survey administration procedure and model specification, the marginal WTP estimates indicate that people are, on average, willing to pay more for solar, wind or RE in general, than specifically for biomass or hydro power. There was no significant difference in WTP between biomass and hydro power. Our study considered household WTP for renewable energy. In that light, preferences for solar energy over other RE sources may be expected because installing photovoltaic panels that generate solar energy is commonly adopted at the household level. As such, households are likely to be more familiar with solar energy and the feasibility of its implementation. However, to test this hypothesis, and to assess the motivational factors behind the support for solar energy, additional research is 44 required.

\footnotetext{
${ }^{5}$ We are grateful to an anonymous reviewer for this observation.
} 
All contingent valuation studies and most choice experiment studies included in the metaregression analysis estimated mean WTP rather than marginal WTP. This is reasonable if the increase in RE-share is small, or if the marginal WTP does not change over the range of increase proposed. However, research has shown that consumers' marginal WTP for green electricity could decrease rather quickly with an increased share of RE in the electricity portfolio. The amount that consumers are willing to pay has been found to be highly nonlinear in the proportion of energy that is generated from renewables (Farhar, 1999). If the marginal benefits decrease with an increasing proportion of RE in the energy mix, a minimum commitment to RE will be sufficient to produce the 'warm glow effect' of its consumption. This is confirmed by real market observations. Ma and Burton (2014) found that Australian consumers' commitment to environmental protection through purchasing green electricity is largely a result of the warm glow effect. Consumers' WTP for RE decreased drastically once some minimum level of commitment to RE was increased. The majority of primary studies do not report information on sample mean income, current electricity consumption, current and proposed RE share in the energy portfolio, and the type of RE considered. For example, some studies propose a renewable energy policy in their stated preference scenario, but do not specify how much electricity would be generated as a result of accepting the policy (see e.g. Bigerna and Polinori, 2011; Bollino, 2009; Hanley and Nevin, 1999; Navrud and Bråten, 2007; Odam, 2011; Soliño, et al. 2009a; Zarnikau, 2003). Given that income, current electricity consumption, current and proposed RE share, and the type of RE explain the true differences in WTP across the population, we cannot directly compare WTP estimates or transfer estimated values without such information. Given governments have limited funds, informed knowledge on the marginal benefits of various types of RE is important to enable governments to target their support where social welfare can be maximised. We recommend future studies specify the RE in the survey, when eliciting people's WTP. Furthermore, researchers are recommended to report information about sample mean income, electricity consumption, and RE shares in future studies. If no studies are available for a specific State or country, policy makers could use benefit transfer to estimate the values for RE. Benefit transfer involves transferring the WTP values from one study site (the source of data) to another (the site of policy interest). This approach would be preferable when it is too expensive or time consuming to conduct an original valuation study. However, we found several limitations in the existing body of RE literature that can limit the usefulness of current WTP estimates for benefit transfer purposes. First, we 
found that existing stated preference studies do not always specify the type of RE, the proportion of RE in the electricity mix, and how an increased share of RE would affect total household electricity bills. Such information can affect respondents’ WTP for RE, and subsequent usefulness for benefit transfer. Second, the wide range of WTP estimates in the RE literature (as shown in Figure 1) could even undermine policy support for RE, as there appears to be no clear consensus on how much people are willing to pay. Third, we found that a large number of primary studies do not report standard error or equivalent dispersion statistics of their WTP estimates. As many point estimates are very close to zero, this practice raises concerns about whether reported WTP estimates reflect significant effects. Studies often jump quickly to drawing welfare and policy implications from the estimated mean or median WTP value without proper reporting or discussion of dispersion statistics. Large WTP variances can translate into an untenable implication that people are willing to pay a large sum of money for RE (Train and Weeks, 2005). The lack of defensibility undermines the reliability and usefulness of such studies.

\section{Conclusion}

This paper presents the findings from a meta-regression analysis of primary studies on the willingness-to-pay (WTP) for various types of renewable energy (RE) and the factors that impact on WTP. The purpose of this study was to find consensus on the effect size and explain what determines heterogeneity in effect sizes. Our study tested the robustness of various (fixed effects and mixed effects) models, and accounts for possible publication and selection bias, as well as heteroscedasticity and within-study dependence. Results from the meta-regression analysis suggest that the main factors affecting WTP are related to survey administration, design and model specification, more so than the factors one would expect to explain true differences in WTP (including RE type, context variables, people's socioeconomic profile and their energy consumption patterns). Following meta-analysis reporting protocols (Nelson and Kennedy, 2009; Stanley et al., 2013) and controlling for survey administration, design and model specification, we show that people have significantly higher WTP for electricity generated from solar, wind or generic (i.e. no indication of a specific source) renewable energy sources than for hydro power or biomass. Additionally, WTP for RE was positively associated with the RE penetration in current energy consumption and the RE share in a proposed energy portfolio, but negatively associated with current household electricity consumption level. We also found that a number of primary studies did not specify 
111 the type of RE being measured, and opted to refer to RE in a generic or conceptual sense.

112 Consequently, it was not possible to attribute WTP to a specific type of RE and limits the

113 ability to transfer the WTP estimates in the future, an important consideration that needs to be 114 looked at in future RE specific WTP studies.

\section{References}

117 Abdullah, S., 2009. Willingness to pay for renewable energy options in developing countries: 118 the case of Kenya. Doctoral Dissertation, Department of Economics and International Development, University of Bath, Bath.

Aldy, J.E., Kotchen, M.J., Leiserowitz, A.A., 2012. Willingness to pay and political support for a US national clean energy standard. Nature Climate Change 2(8), 596-599.

Aravena, C., Hutchinson, W.G.,Longo, A., 2012. Environmental pricing of externalities from different sources of electricity generation in Chile. Energy Economics 34(4), 12141225.

Bateman, IJ, Carson, RT, Day, B, Hanemann, M, Hanley, N, Hett, T, Jones-Lee, M, Loomes, valuation with stated preference techniques: a manual, Edward Elgar, Cheltenham, UK.

Batley S.L, Colbourne, D., Fleming, P.D., Urwin, P., 2001. Citizen versus consumer: challenges in the UK green power market. Energy Policy 29(6), 479 - 87.

Begg, C.B., Mazumdar, M., 1994. Operating characteristics of a rank correlation test for publication bias. Biometrics 50, 1088-1101.

Begg, C.B., Berlin, J.A., 1988. Publication bias: a problem in interpreting medical data. Journal of Royal Statistical Society151, 419-445.

Bigerna, S., Polinori, P., 2011. Italian consumers’ willingness to pay for renewable energy sources. USAEE-IAEE Working Paper, 11-094.

Bloom, P.N., Novelli, W.D., 1981. Problems and challenges in social marketing. The Journal of Marketing, 79-88. with socio-demographic determinants. Energy Journal 30(2), 81-96. 
Borchers, A.M., Duke, J.M., Parsons, G.R., 2007. Does willingness to pay for green energy differ by source? Energy Policy 35(6), 3327-3334.

Boyle, K.J., Johnson, F.R., McCollum, D.W., Desvousges, W.H., Dunford, R.W., Hudson, S.P., 1996. Valuing Public Goods: Discrete versus Continuous Contingent-Valuation Responses. Land Economics 72(3), 381-396.

Byrnes, B., Jones, C., Goodman, S., 1999. Contingent valuation and real economic commitments: evidence from electric utility green pricing programmes. Journal of Environmental Planning and Management 42(2), 149-166.

Cicia, G., Cembalo, L., Del Giudice, T., Palladino, A., 2012. Fossil energy versus nuclear, wind, solar and agricultural biomass: Insights from an Italian national survey. Energy Policy 42, 59-66.

Egger, M., Smith, G.D., Schneider, M., Minder, C., 1997. Bias in meta-analysis detected by a simple, graphical test. British Medical Journal 315, 629-634.

Ek K., 2005. Public and private attitudes towards green electricity: the case of Swedish wind power. Energy Policy 33(13),1677 - 89.

155

156

Farhar, B., 1999, Willingness to Pay for Electricity from Renewable Resources: A Review of Utility Market Research, NREL/TP.550.26148. Golden, CO: National Renewable Energy Laboratory, USA.

Feenstra, Robert C., Inklaar, R.,and Timmer, M.P.2013, The Next Generation of the Penn World Table. Available for download at www.ggdc.net/pwt.

Field, A.P., Gillett, R., 2010. How to do a meta-analysis. British Journal of Mathematical and Statistical Psychology 63(3), 665-694.

Glass G.V., 1976. Primary, secondary, and meta-analysis of research. Educ Res 10, 3-8.

Gracia, A., Barreiro-Hurlé, J., Pérez y Pérez, L., 2012. Can renewable energy be financed with higher electricity prices? Evidence from a Spanish region. Energy Policy 50, 784-794.

Hanemann, M., Labandeira, X., Loureiro, M.L., 2011. Climate change, energy and social preferences on policies: exploratory evidence for Spain. Climate Research 48(2-3), 343-348. 
Hanley, N., Nevin, C., 1999. Appraising renewable energy developments in remote communities: the case of the North Assynt Estate, Scotland. Energy Policy 27(9), 527-547

Higgins, J.P.T., Thompson, S.G., 2004. Controlling the risk of spurious findings from metaregression. Statistics in Medicine 23, 1663-1682.

Hite, D., Duffy, P., Bransby, D., Slaton, C., 2008. Consumer willingness-to-pay for biopower: Results from focus groups. Biomass and Bioenergy 32(1), 11-17.

IPCC, 2014. Summary for Policymakers, In: Edenhofer, O., R. Pichs-Madruga, Y. Sokona, E. Farahani, S. Kadner, K. Seyboth, A. Adler, I. Baum, S. Brunner, P. Eickemeier, B. Kriemann, J. Savolainen, S. Schlömer, C. von Stechow, T. Zwickel and J.C. Minx (Eds.), Climate Change 2014, Mitigation of Climate Change. Contribution of Working Group III to the Fifth Assessment Report of the Intergovernmental Panel on Climate Change. Cambridge University Press, Cambridge, United Kingdom and New York, NY, USA.

Ivanova, G., 2005. Queensland consumers' willingness to pay for electricity from renewable energy sources. Australia New Zealand Society for Ecological Economics (ANZSEE) Conference, Massey University, New Zealand.

Ivanova, G., 2012. Are consumers' willing to pay extra for the electricity from renewable energy sources? An example of Queensland, Australia. International Journal of Renewable Energy Research 2(4), 758-766.

Kaenzig, J., Heinzle, S.L., Wüstenhagen, R., 2013. Whatever the customer wants, the customer gets? Exploring the gap between consumer preferences and default electricity products in Germany. Energy Policy 53, 311-322.

Kim, J., Park, J., Kim, H., Heo, E., 2012. Assessment of Korean customers’ willingness to pay with RPS. Renewable and Sustainable Energy Reviews 16(1), 695-703.

Koetse, M., Florax, R., Groot, H., 2010. Consequences of effect size heterogeneity for metaanalysis: a Monte Carlo study. Statistical Methods and Applications 19(2), 217-236.

Komarek, T.M., Lupi, F., Kaplowitz, M.D., 2011. Valuing energy policy attributes for environmental management: Choice experiment evidence from a research institution. Energy Policy 39(9), 5105-5115. 
Kontogianni, A., Tourkolias, C., Skourtos, M., 2013. Renewables portfolio, individual preferences and social values towards RES technologies. Energy Policy 55, 467-476.

Kosenius, A.K., Ollikainen, M., 2013. Valuation of environmental and societal trade-offs of renewable energy sources. Energy Policy 62, 1148-1156.

Ma, C., Burton M., 2014. The Public's Preference for Green Power in Australia, Australian Agricultural and Resource Economics Society Conference, Port Maquarie.

MacMillan, D., Hanley, N., Lienhoop, N., 2006. Contingent valuation: environmental polling or preference engine? Ecological Economics 60(1), 299-307.

Moomaw, W., Yamba, F., Kamimoto, M., Maurice, L., Nyboer, J., Urama, K., Weir, T., 2011. Introduction. In: Edenhofer, O., Pichs-Madruga, R., Sokona, Y., Seyboth, K., Matschoss, P., Kadner, S., Zwickel, T., Eickemeier, P., Hansen, G., Schlömer, S., von Stechow C., (Eds.), IPCC Special Report on Renewable Energy Sources and Climate Change Mitigation. Cambridge University Press, Cambridge, United Kingdom and New York, NY, USA.

Morrison, M., Bennett, J., Blamey, R., Louviere, J., 2002. Choice modelling and tests of benefit transfer. American Journal of Agricultural Economics 84(1), 161-170.

Navrud, S., Bråten, K. G. 2007. Consumers' Preferences for Green and Brown Electricity: a Choice Modelling Approach. Revue D'économie Politique 117(5), 795-811.

Nelson, J.P., Kennedy P.E., 2009. The Use (and Abuse) of Meta-Analysis in Environmental and Natural Resource Economics: An Assessment. Environmental and Resource Economics 42, 345-377.

Nomura, N., Akai, M., 2004. Willingness to pay for green electricity in Japan as estimated through contingent valuation method. Applied Energy 78(4), 453-463.

Odam, N., 2011. Developing infant technologies in mature industries: A case study on renewable energy. University of Stirling, Scotland.

Roe B., Teisl M.F., Levy A., Russell M., 2001. US consumers’ willingness to pay for green electricity. Energy Policy 29(11), 917 - 25.

Rosenthal, R.,1991. Effect sizes: Pearson’ correlation, its display via the BESD, and alternative indices. American Psychologist 46, 1086-1087. 
Rothschild, M.L., 1979. Marketing communications in nonbusiness situations or why it's so hard to sell brotherhood like soap. The Journal of Marketing, 11-20.

Soliño, M., Vázquez, M., Prada, A., 2009a. Social demand for electricity from forest biomass in Spain: Does payment periodicity affect the willingness to pay? Energy Policy 37, 531-540.

Soliño, M., Farizo, B.A., Campos, P., 2009b. The influence of home-site factors on residents' willingness to pay: An application for power generation from scrubland in Galicia, Spain. Energy Policy 37(10), 4055-4065.

Stanley, T.D., 2001. Wheat from chaff: meta-analysis as quantitative literature review. Journal of Economic Perspectives 15, 131-150.

Stanley, T.D., Doucouliagos, H,. Giles, M., Heckemeyer, J.H., Johnston, R.J., Laroche, P., Nelson, J.P., Paldam, M., Poot, J., Pugh, G., Rosenberger, R.S., Rost, K., 2013. MetaAnalysis of Economics Research Reporting Guidelines. Journal of Economic Surveys 27(2), 390-394.

Stanley, T.D., 2005. Beyond publication bias. Journal of Economic Surveys 19, 309-345.

Stanley, T.D., 2008. Meta-regression methods for detecting and estimating empirical effects in the presence of publications election. Oxford Bulletin of Economics and Statistics 70(1), 103-127.

Stanley, T.D., Rosenberger, R.S., 2009. Are recreational values systematically underestimated? Reducing publication selection bias for benefit transfer. Paper presented at the Oregon State MAER-Net Colloquium. Oct 2, 2009.

Steichen, T.J., 1998. Tests for publication bias in meta-analysis. The Stata Technical Bulletin $41,9-15$

Sundt, S, Rehdanz, K., 2014. Consumer’s Willingness to Pay for Green Electricity: A MetaAnalysis of the Literature, Kiel Working Papers 1931, Kiel Institute for the World Economy.

Susaeta, A., Lal, P., Alavalapati, J., Mercer, E., 2011. Random preferences towards bioenergy environmental externalities: A case study of woody biomass based electricity in the Southern United States. Energy Economics 32, 1111-1118. 
Thompson, S.G., Sharp, S.J., 1999. Explaining heterogeneity in meta-analysis: a comparison of methods. Statistics in Medicine 18, 2693-2708.

Train, K., Weeks, M. 2005. Discrete choice models in preference space and willingness-topay space, In: Alberini, A. and Scarpa, R. (Eds.), Applications of simulation methods in environmental and resource economics. Kluwer Academic Publishers, Boston.

Wei, M., Patadia, S., Kammen, D.M., 2010. Putting renewables and energy efficiency to work: How many jobs can the clean energy industry generate in the US?. Energy Policy 38(2), 919-931.

Welsh, M.P., Poe, G.L., 1998. Elicitation Effects in Contingent Valuation: Comparisions to a Multiple Bounded Discrete Choice Approach. Journal of Environmental Economics and Management 36, 170-185

Wiener, J.L., Doescher, T.A., 1991. A framework for promoting cooperation. The Journal of Marketing 55, 38-47.

Wiser, R.H., 1998. Green power marketing: increasing customer demand for renewable energy. Utilities Policy 7(2), 107-119.

Yoo, S.H., Kwak, S.Y., 2009. Willingness to pay for green electricity in Korea: A contingent valuation study. Energy Policy 37(12), 5408-5416.

Zarnikau, J., 2003. Consumer demand for 'green power'and energy efficiency. Energy Policy 31(15), 1661-1672.

Zhang, L., Wu, Y., 2012. Market segmentation and willingness to pay for green electricity among urban residents in China: The case of Jiangsu Province. Energy Policy 51, 514-523.

Zografakis, N., Sifaki, E., Pagalou, M., Nikitaki, G., Psarakis, V., Tsagarakis, K.P., 2010. Assessment of public acceptance and willingness to pay for renewable energy sources in Crete. Renewable and Sustainable Energy Reviews 14(3), 1088-1095. 